\title{
Rete Ovarii Adenoma
}

National Cancer Institute

\section{Source}

National Cancer Institute. Rete Ovarii Adenoma. NCI Thesaurus. Code C40018.

An adenoma that arises from the rete ovarii. It is composed of elong ated tubules. The clinical course is benign. 